\title{
Cinco premisas en torno a la metamorfosis del IFE en autoridad electoral nacional
}

\author{
Five Premises Around IFE's Metamorphosis \\ as the National Electoral Regulatory Body
}

\section{César Astudillo*}

\section{Sumario:}

I. Introducción

II. La modificación de la naturaleza de la autoridad electoral. De la gestión del proceso electoral al control de la regularidad de las elecciones

III. El cambio en sus objetivos. Del recuento confiable de los votos al auspicio de las condiciones ambientales para la emisión del sufragio en condiciones democráticas

IV. La reorientación de sus exigencias. De ser un árbitro técnico, neutral, discreto y eficaz a constituirse en un actor político fundamental y protagónico del juego democrático

V. El viraje de sus fines. De ser una institución para la transición política a convertirse en pieza clave de la consolidación democrática

VI. El redimensionamiento de la autoridad electoral. De un alcance exclusivamente federal a una auténtica dimensión nacional

VII. Reflexión final

* Investigador en el Instituto de Investigaciones Jurídicas de la UNAM. Agradezco el apoyo brindado en la revisión de este artículo al maestro Marcos I. Martínez Alcázar y al licenciado Juan Carlos Chávez. 


\section{Resumen:}

El artículo pretende explicar a través de cinco premisas las grandes transformaciones de la autoridad electoral de México en sus más de 23 años de funcionamiento, con el objetivo de patentizar que al finalizar su ciclo de vida institucional, aparecía ya como una institución notablemente diferente a aquélla surgida en los años noventa.

En este sentido, contiene un recorrido que enfatiza algunos elementos clave dirigidos a explicar esa "metamorfosis institucional", que a partir de los cambios a su naturaleza, objetivos, exigencias y fines movieron al Instituto Federal Electoral del espacio institucional en el que nació, y que paulatinamente produjeron el ensanchamiento de sus alcances a través de un conjunto de nuevas responsabilidades que con el paso del tiempo produjeron una evidente sobrerregulación, pero sobre todo, un notable redimensionamiento del margen de actuación del IFE.

Este conjunto de cambios, vistos integralmente y a la distancia, fueron preparando el terreno para la transformación de la autoridad electoral en una institución que de una responsabilidad circunscrita al ámbito de las elecciones federales adquirió un auténtico carácter nacional mediante un esquema competencial que le permite tomar decisiones en el contexto de los comicios estatales y municipales.

\section{Abstract:}

This article seeks to explain, through five premises, the major transformations of the Mexican electoral authority. The goal is to emphasize that after 23 years of operations, at the end of its life cycle, this institution was notably different from what it was when it first arose in the 1990s.

In this sense, this work emphasizes some key elements that explain this "institutional metamorphosis". Changes in its nature, objectives, demands and end goals moved the Instituto Federal Electoral (IFE) out of the institutional space in which it was conceived. New responsibilities led to a clear over-regulatory role and, above all, a notable increase in IFE's scope of action.

When evaluated as a whole and with proper perspective, it is clear that these changes paved the way for the transformation of the electoral regulatory body. It started as an institution with a limited role in federal election contests to one with national influence given that its competence framework allows it to rule in the context of local and state election contests.

Palabras clave: reformas electorales, reforma electoral 2014, modelo de organización electoral, elecciones, IFE, INE.

Key words: electoral reforms, 2014 electoral reform, model of electoral organization, elections, IFE, INE. 


\section{Introducción}

Desde una perspectiva integral, el ciclo de vida institucional comprendido entre el 11 de octubre de 1990 y el 5 de abril de 2014 se distingue, sin asomo de duda, por la profunda transformación de la función para la cual el Instituto Federal Electoral (IFE) fue históricamente concebido. ${ }^{1}$

Las reformas que sucedieron al momento fundacional de 1990 fueron modificando el papel bajo el que inicialmente se imaginó a la autoridad electoral, a través de sucesivos ajustes que se produjeron como consecuencia de acontecimientos de orden social, político, institucional y económico, así como de coyunturas particulares de cada momento histórico, que involucraron al IFE en un tránsito caracterizado por la carencia de una hoja de ruta cierta y predeterminada en torno a las expectativas a alcanzar en el corto, mediano y largo plazo, pero que en sus más de 23 años de existencia, abonó a la edificación de una autoridad electoral sensiblemente distinta a aquella concebida originalmente.

En los inicios de su ciclo de vida institucional, el IFE se erigió con la exigencia de que su andadura institucional procurara el ejercicio del sufragio en sentido formal. Acaso por ello, apareció como una instancia encargada de la "organización" de las elecciones federales, a la que se confió la gestión de las actividades "típicas" surgidas de la dinámica electoral. Su función inicial quedó así nítidamente orientada a realizar un importante despliegue organizativo de carácter técnico, tendiente a posibilitar la oportuna emisión del sufragio y a contabilizar de manera efectiva los votos emitidos. Al cierre del ciclo lo que ocurría era diametralmente distinto, ya que la institución se había convertido en promotor del sufragio en sentido sustancial, al presentarse con la trascendental encomienda de auspiciar las condiciones ambientales para que el voto popular se ejercitara bajo las calidades democráticas exigidas por la Constitución.

Si se acepta este ejercicio de traslación, es necesario reconocer que en sus poco más de 23 años de existencia el IFE vivió una auténtica mutación que se advierte en la modificación de su naturaleza, el replanteamiento de sus objetivos, el ajuste de sus fines y el redimensionamiento de las exigencias depositadas en su andamiaje institucional, todo lo cual fue progresivamente preparando el terreno para el cambio ulterior, que

1 En esas fechas se llevaron a cabo las sesiones inaugural y de clausura del IFE respectivamente. 
de conformidad con la más reciente reforma electoral, terminó por redimensionar el ámbito de actuación, ahora nacional, de una renovada autoridad electoral - en función de su reciente certificado de nacimiento-, pero heredera de un bagaje, una arquitectura institucional y una experiencia notablemente avanzadas por el IFE.

A continuación se realizará un recorrido que enfatiza en algunos elementos clave que permiten explicar la "metamorfosis" que en el ámbito temporal ya referido movió al IFE del espacio institucional en el que nació hacia un paulatino ensanchamiento de sus alcances y de sus responsabilidades al interior de la democracia mexicana.

\section{La modificación de la naturaleza de la autoridad electoral. De la gestión del proceso electoral al control de la regularidad de las elecciones}

Al inicio de su ciclo de vida institucional el IFE tuvo como misión fundamental infundir confianza en las elecciones. Acaso por ello, a partir de 1990 fue el auténtico depositario de la "organización" de los comicios federales, ${ }^{2}$ lo que implicó la primigenia responsabilidad de conducir cada tramo de la organización electoral con estricto apego a la legalidad, bajo parámetros técnicos y progresivamente más profesionales. ${ }^{3} \mathrm{Al}$ finalizar su ciclo de funcionamiento nos encontramos ante una autoridad electoral notoriamente desplazada de ese inicial eje de equilibrio, ya que más allá de su faceta de autoridad electoral de naturaleza administrativa se terminó posicionando como una instancia cuasi-jurisdiccional derivado del conjunto de atribuciones conferidas para controlar la regularidad de los actos electorales y sancionar la comisión de infracciones constitucionales y legales cometidas por el conjunto de actores que confluyen en los procesos electorales.

2 Desde la inicial mención del ámbito de actuación de la autoridad electoral en el artículo 41 constitucional se confirió al IFE la "organización de las elecciones federales". A partir de entonces, la autoridad electoral se convirtió en recipiendaria de la función estatal de organizar las elecciones para renovar a los poderes Legislativo y Ejecutivo de la Unión. Al respecto, Becerra, Ricardo et al., La mecánica del cambio político en México. Elecciones, partidos y reformas, 3a. ed., México, Cal y Arena, 2005, pp. 249 y ss.

3 Al respecto, Woldenberg, José, La construcción de la democracia, México, Plaza \& Janes, 2002, p. 47. 
Las actividades típicas de la función electoral ${ }^{4}$ adquirieron en las reformas constitucionales de 1994, p ero sobre todo en la de 1996, una incontestada institucionalización que se produjo como consecuencia de una gestión electoral asentada en la plena autonomía e independencia reconocida a la autoridad electoral. ${ }^{5}$ A partir del espacio de actuación institucional que ambas reformas reservaron al IFE, éste lograría rescatar la experiencia y el profesionalismo acumulados durante una década para hacer de los comicios mecanismos creíbles para la renovación periódica del presidente de la República y de los senadores y diputados del Congreso de la Unión, tal y como se demostró en las elecciones generales del año $2000 .^{6}$

Sin embargo, el advenimiento de problemas atípicos de la función electoral derivados de la reproducción de actores políticos, el aumento de la competitividad entre partidos y la intensificación de la conflictividad electoral se manifestaron con toda su intensidad en las elecciones presi-

4 Actividades entre las que destacan la definición de la geografía electoral, la actualización del padrón electoral, el registro de plataformas electorales, de candidatos y representantes de los partidos políticos, la selección y capacitación de los funcionarios de casilla, la determinación del número y ubicación de los centros de votación, la conformación de las mesas directivas de casilla, la papelería y los materiales para la jornada electoral, la instalación y apertura de casillas, el escrutinio y cómputo de los votos, los sistemas de transmisión de resultados electorales, la determinación de los resultados y la declaración de validez de los comicios - excepto de las elecciones presidenciales-. Como señala José Woldenberg en su artículo “¿Instituto Nacional Electoral?”, "desde hace un buen rato las diferencias entre los partidos y el IFE en materia de organización de las elecciones es casi inexistente", en Astudillo, César (coord.), Instituciones electorales nacionales a debate, México, Tirant lo Blanch, 2013, p. 269. No debe pasar desapercibido que entre 1990 y 1993 la propia autoridad electoral impulsó los aspectos operativos del proceso electoral al aprobar, por ejemplo, el modelo de credencial para votar con fotografía o los modelos de credencial para votar. Sobre este particular acúdase a Andrade, Virgilio, "IFE: de administrador a árbitro electoral”, Nexos, México, núm. 372, diciembre de 2008, consultable en $h t t p: / / h i s t o r i c o . n e x o s . c o m . m x / v e r s \_i m p . p h p$ ? id_article $=1153$ sid_rubrique $=423$.

5 La forma en que las reformas de 1994 y 1996 coadyuvaron a la institucionalización de las funciones típicas de la organización electoral se narra, por ejemplo, en Carpizo, Jorge, "Informe que se presenta al Colegio Electoral de la H. Cámara de Diputados del Congreso de la Unión”, Revista Mexicana de Derecho Electoral, México, núm. 2, juliodiciembre de 2012, pp. 394 y ss.; Becerra, Ricardo et al., La reforma electoral de 1996: una descripción general, México, Fondo de Cultura Económica, 1997.

6 Como acertadamente señala Guerrero Aguirre, "se le aplaude al IFE su desempeño en el 2000, se le reconoce su profesionalismo, su imparcialidad y su independencia, la alternancia no le resta credibilidad y la sociedad le entrega su confianza". "El modelo electoral mexicano en retrospectiva. Balance de lo alcanzado en 23 años", en Astudillo, César, Instituciones electorales nacionales..., cit., p. 126. 
denciales de 2006, dejando al descubierto conductas claramente lesivas de la equidad de la contienda y un entramado institucional carente de reglas de contención para atajar con oportunidad las irregularidades cometidas, por ejemplo, la realización de actos anticipados de campaña, la instrumentación de campañas negativas, la injerencia de los poderes públicos en las campañas, la utilización de programas sociales con propósitos electorales, la influencia de la radio y la televisión en la equidad de la contienda, la excesiva difusión de propaganda gubernamental, entre otros. $^{7}$

Con el propósito de contrarrestar esta realidad, la reforma constitucional y legal de 2007 estableció una contundente regulación en materia de infracciones y sanciones electorales. ${ }^{8}$ Por un lado, se definió el catálogo de sujetos sancionables por su papel protagónico al interior del proceso electoral - partidos políticos, dirigentes, candidatos, precandidatos, aspirantes, militantes, ciudadanos-, así como una amplia gama de sujetos con un papel indirecto pero igualmente trascendente - observadores, encuestadoras, medios de comunicación, poderes públicos, notarios, extranjeros, organizaciones sindicales, ministros de culto, etcétera-; por otro lado, se definió un abanico de conductas irregulares dentro de materias tan significativas como la propaganda política e institucional y los actos anticipados de precampaña y campaña, regulados con detenimiento por la misma reforma. ${ }^{9}$

El renovado régimen sancionador electoral vino a modificar sustancialmente la originaria naturaleza del IFE, y a trastocar el principio de es-

7 Instituto Federal Electoral, Elecciones federales 2006, México, IFE, 2006, p. 11.

8 El régimen sancionador tiene su génesis en la inclusión de un conjunto de "faltas administrativas" en el Cofipe de 1990. Sin embargo, fue la reforma de 1996 la que estipuló infracciones cometidas por ciudadanos, observadores electorales, poderes públicos, funcionarios electorales, notarios, extranjeros, partidos políticos y sus dirigentes (artículos 264-270). El Cofipe de 2008 realizó la sistematización del catálogo de sujetos, conductas sancionables y sanciones en su libro séptimo (artículos 340 a 355). Una aproximación a la evolución del régimen sancionador electoral se encuentra en Alanís Figueroa, María del Carmen, "La jurisprudencia del TEPJF: fuente formal de la reforma electoral 2007-2008”, en Córdova Vianello, Lorenzo y Salazar Ugarte, Pedro (coords.), Estudios sobre la reforma electoral 2007. Hacia un nuevo modelo, México, Tribunal Electoral del Poder Judicial de la Federación, 2008, pp. 33 y ss.; Guerrero Aguirre, Francisco Javier, El modelo sancionador de quejas y denuncias y el control de la legalidad, Veracruz, Instituto Electoral Veracruzano, 2013, pp. 65 y ss.

9 Córdova Vianello, Lorenzo, "La reforma electoral de 2007-2008 cuatro años después. Apuntes para un balance de su instrumentación”, Revista Mexicana de Derecho Electoral, México, núm. 1, enero-junio de 2012, p. 15. 
pecialización característico del modelo mexicano de organización electoral que desde la década de los noventa separó las actividades de gestión y control de los comicios en el IFE como principal instancia administrativa y en el Tribunal Electoral como órgano jurisdiccional por antonomasia. ${ }^{10}$

La reforma confirió al IFE un conjunto de atribuciones que en estricto sentido son de carácter contencioso, ${ }^{11}$ transfiriéndole la capacidad de controlar la regularidad jurídica de los distintos actos que componen cada eslabón, etapa o fase en que se articula el proceso electoral, al interior del cual destacan materias particularmente relevantes como el financiamiento de los partidos, el acceso a los medios de comunicación social, los procesos partidistas de selección y postulación de candidatos, las precampañas y campañas, la fiscalización de los partidos, las sanciones administrativas a los servidores públicos, etcétera.

Este tipo de atribuciones, que con base en su especificidad han sido adjetivadas como materialmente jurisdiccionales o cuasi-jurisdiccionales, ${ }^{12}$ impactaron profundamente el andamiaje institucional del IFE. Para su ejercicio se comprometió a la entera estructura - centralizada y descentralizada - de la institución electoral, mediante la instauración de un renovado procedimiento de substanciación caracterizado por su extrema expeditez y que día a día fue articulando una plataforma interpretativa

10 Sobre el principio de especialización como característica del modelo mexicano de organización electoral, acúdase a Astudillo, César, "El modelo de organización electoral en México", en id. y Carpizo, Jorge (coords.), Constitucionalismo. Dos siglos de su nacimiento en América Latina, México, UNAM-Instituto Iberoamericano de Derecho Constitucional, 2013, pp. 757-793.

11 Este tipo de control se caracteriza por su carácter administrativo con base en el tipo de órgano bajo el que se sustancia y resuelve, y tiene una naturaleza punitiva porque a través de él se imponen penalidades o sanciones a quien haya cometido una irregularidad castigada por la legislación electoral. Es un control de tipo "represivo" o "inhibidor" que castiga o sanciona al sujeto responsable de la infracción electoral. Silva Adaya, Juan Carlos, "El derecho administrativo sancionador electoral y el Estado constitucional y democrático de derecho en las sentencias del Tribunal Electoral", en Ferrer Mac-Gregor, Eduardo y Zaldívar Lelo de Larrea, Arturo (coords.), La ciencia del derecho procesal constitucional. Estudios en Homenaje a Héctor Fix-Zamudio en sus cincuenta años como investigador del derecho, México, Instituto Mexicano de Derecho Procesal ConstitucionalMarcial Pons-UNAM, Instituto de Investigaciones Jurídicas, 2008, t. VI, pp. 895 y ss. También, Orozco Henríquez, J. Jesús, El contencioso electoral en las entidades federativas de México, Tesis doctoral, México, UNAM, Instituto de Investigaciones Jurídicas, 2009, p. 60.

12 Por ejemplo, Woldenberg, José, "El IFE como juez", Reforma, México, 18 de junio de 2009, p. 12; Morales Manzanares, Rodrigo, "Nuevas atribuciones del IFE. De cómo vino la reforma, cómo se aplicó y qué está faltando", Temas selectos de derecho electoral, México, núm. 16, Tribunal Electoral del Poder Judicial de la Federación, 2010, p. 36. 
que en función de las materias discutidas en su interior, produjo la convulsión de la dinámica comicial, ya que más allá de resolver cuestiones vinculadas con la organización de las elecciones, terminó por centrarse reiteradamente en el análisis de los spots electorales a partir de la interpretación del alcance de derechos fundamentales como la libertad de expresión, información, o los derechos político-electorales. ${ }^{13}$

Este régimen competencial, en definitiva, produjo un efecto adverso, ya que por un lado persistía la necesidad histórica de que la autoridad electoral contara con las mejores condiciones para articular consensos y construir vínculos de confianza con los actores políticos, pero por otro, se le obligaba a desplegar una potestad sancionadora hacia ellos, que cada vez era más frecuente y mucho más intensa en sus repercusiones.

El cumplimiento del nuevo marco de actuación institucional terminó por situar a la autoridad electoral en un polo diametralmente distinto al original, en donde más que árbitro apareció como juez de la contienda política, por su capacidad para resolver disputas entre los partidos, en situación de tercero neutral, a partir de la aplicación de las normas a los casos controvertidos y de conformidad con la valoración de los hechos acreditados ante él. ${ }^{14}$ Quizá por ello, al final de su ciclo de vida el

13 En el proceso electoral federal de 2006 se radicaron 1022 procedimientos especiales sancionadores (PES), 361 ante la Secretaría Ejecutiva del IFE y 661 ante los consejos distritales. Durante el proceso electoral federal de 2009, se recibieron 1026, de los cuales 663 fueron atendidos por las juntas y los consejos distritales, y 363 a nivel central. Véase Informe general sobre la implementación de la reforma electoral, durante el proceso 20082009, México, Instituto Federal Electoral, 2010, p. 131. Para las elecciones generales de 2012 se recibieron 1371 PES; 925 se radicaron en las Juntas Distritales y 446 en la Secretaría Ejecutiva del IFE. Véase Libro Blanco. Proceso Electoral Federal 2011-2012, México, Instituto Federal Electoral, 2013, pp. 64, 208 y ss.; Sobre el incremento de la función sancionadora, véase Zavala Arredondo, Marco Antonio, "A salto de mata. Los procedimientos especiales sancionadores y el proceso electoral 2011-2012", Revista Mexicana de Derecho Electoral, México, núm. 3, enero-junio de 2013, p. 241; Guerrero Aguirre, Francisco Javier, "Los retos del IFE rumbo a las elecciones de 2012", Revista Mexicana de Derecho Electoral, México, núm. 1, enero-junio de 2012, pp. 307-324. Hasta el 2 de abril de 2015, la nueva Sala Regional Especializada ha tenido conocimiento de 278 quejas, de las cuales 147 son PES.

14 Tal y como apunta Guerrero Aguirre: "En estricto ejercicio de estas facultades sancionatorias, el rostro ciudadano del IFE ahora ha adquirido un matiz de autoridad administrativa sancionadora, que para algunos, es ya la primera instancia de una actividad jurisdiccional electoral, que incluye facultades de investigación, desahogo y valoración de pruebas e imposición de sanciones", "Los retos del IFE...”, cit., p. 312. En esa misma línea se inscribe lo que señala Morales Manzanares al considerar que: "El IFE dejó de ser la institución que organizaba las elecciones para convertirse en el espacio que regula y san- 
IFE mantenía su empeño en la organización de las elecciones, pero había modificado diametralmente su estructura y competencias para juzgar y sancionar aquellas conductas que con motivo de su ilicitud, lastimasen la adecuada consecución del ejercicio comicial.

En este sentido, como sostuvo en su momento Córdova Vianello, valía "la pena pensar si un órgano cuya función principal es la de organizar elecciones debe ser el que cumpla esa tarea de vigilancia y supervisión de actores que incide en los procesos electorales pero cuya naturaleza trasciende ese ámbito". ${ }^{15}$

Precisamente por los efectos distorsionadores generados por el modelo sancionador, la reforma electoral de 2014 instrumentó un esquema distinto que compromete al Instituto Nacional Electoral (INE) en la investigación de las infracciones y al Tribunal Electoral del Poder Judicial de la Federación (TEPJF) mediante su nueva Sala Especializada, en la resolución de los procedimientos. ${ }^{16}$

Evidentemente este esquema híbrido no afecta el cambio de naturaleza que ha experimentado la institución electoral, pero sí atempera su papel como juez de las infracciones electorales.

\section{El cambio en sus objetivos. Del recuento confiable de los votos al auspicio de las condiciones ambientales para la emisión del sufragio en condiciones democráticas}

En los inicios de su andadura institucional, el IFE apareció como una institución diseñada para la organización técnica y profesional de los comicios y para el recuento efectivo y confiable de los sufragios. Luego de 23 años de funcionamiento, asistimos a un profundo cambio en los objetivos originalmente planteados, ya que más allá de su función instrumental en beneficio de la participación política del ciudadano, el IFE reivindicó

ciona todo lo que tiene que ver con los procesos asociados con los comicios..., "Nuevas atribuciones del IFE. De cómo vino la reforma..., cit., p. 34. Finalmente, como lo indica Andrade, "el ser juzgador y sancionador directo ha colocado al IFE en un plano distinto de autoridad, que además de organizar pretende corregir e inhibir conductas ilícitas. En una frase: impartir justicia”. Andrade, Virgilio, "IFE: De administrador a árbitro...", cit.

15 Córdova Vianello, Lorenzo, "La reforma electoral de 2007-2008..., cit., p. 19.

16 Este modelo sancionador de carácter híbrido tiene su fundamento en el artículo 41 apartado D y 99, fracción IX de la Constitución. El PES está regulado en los artículos 470 al 477 de la LGIPE. 
su carácter de "autoridad en la materia", y con ello, la responsabilidad de auspiciar las condiciones ambientales propicias para la emisión del sufragio en condiciones democráticas.

Los sucesos que acompañaron a la competida elección presidencial de 1988, entre los que destaca la ausencia de una institución electoral independiente y la sospecha de acciones fraudulentas surgidas con motivo de la "caída del sistema", derivaron en un acuerdo político fundacional a favor de la construcción de una nueva institucionalidad electoral. La organización de los comicios bajo parámetros técnicos - no políticos-, el recuento efectivo y confiable de los votos emitidos en elecciones federales y la construcción de confianza en el imaginario colectivo se convirtieron en los objetivos primigenios del naciente IFE. ${ }^{17}$

Ante esas exigencias primarias, la constatación de la calidad -libre y razonada, o bien coaccionada o informada - con la que el ciudadano acudía a sufragar quedó relegada a un segundo plano; tampoco fue prioritario que las elecciones discurrieran a partir de una elemental paridad de condiciones en la competencia política. Se objetaba, en efecto, pero no era trascendental para ese momento histórico, la ausencia de equidad en el acceso de los partidos políticos a los medios de comunicación, en el financiamiento público y en la cobertura noticiosa equilibrada y plural. ${ }^{18}$

El escenario de fin de ciclo nos sitúa ante una realidad notoriamente diferente. No hay duda que la exigencia de un recuento confiable de los sufragios y la necesidad de infundir credibilidad y confianza en la actuación institucional del IFE permanecieron como condición inexorable durante estas dos décadas. El asentamiento de la competitividad entre los partidos y la falta de mecanismos para procesar resultados tan cerrados como los que se presentaron en las elecciones presidenciales de 2006 - las repercusiones del "voto por voto, casilla por casilla" - , volvieron a hacer de la desconfianza el elemento característico de nuestra organización electoral, y motivaron que la reforma del año siguiente incorporara reglas para reforzar el recuento de los votos ante una diferencia mínima entre los principales competidores. ${ }^{19}$

17 Véase Woldenberg, José, “La ciudadanización del IFE”, Instituto Federal Electoral 20 años, México, IFE-Conacyt, 2010, p. 157.

18 Véase Aguirre, Pedro et al., José, Sistemas políticos, partidos y elecciones, México, Trazos-Instituto de Estudios para la Transición Democrática, 1993, p. 291.

19 La reforma de 2007 incorporó el recuento parcial y total de votos cuando la diferencia entre el primero y el segundo lugar fuese menor a un punto porcentual. Sobre el particular, Tapia, Cecilia, "Regulación del proceso electoral", en Córdova Vianello, Lorenzo y Salazar Ugarte, Pedro (coords.), Estudios sobre la reforma..., cit., pp. 398 y ss.; 
Pero más allá de las implicaciones de este ajuste, lo que interesa destacar es que con motivo del fortalecimiento del pluralismo, la institucionalización del sistema de partidos, el ensanchamiento de la equidad en los comicios y la consolidación de la autoridad electoral federal, es evidente que en el último tramo de existencia del IFE ya no resultaba indiferente la forma de emisión del sufragio ciudadano, ni el contexto en el que los partidos políticos enfrentaban los comicios, con lo cual, proceder al escrutinio de los votos emitidos en un contexto carente de los más esenciales referentes democráticos, constituía un ejercicio contrario a la renovada lógica electoral.

Acaso por ello, a más de dos décadas de distancia, entre las tareas esenciales del IFE aparecían aquellas que mostraban su compromiso a favor del auspicio de condiciones ambientales para que los partidos políticos accedieran a la contienda bajo una elemental paridad de condiciones, y para que los ciudadanos acudieran a emitir su voto en un entorno propicio para la expresión auténtica, libre, efectiva y genuina de su voluntad.

No se trata de destacar en este punto aquellas responsabilidades establecidas en la ley y a las que había que dar cabal cumplimiento, sino más bien aquellas iniciativas auspiciadas exitosamente por el IFE a partir de su redimensionamiento como autoridad en materia electoral y que a lo largo de 23 años influyeron positivamente en el reequilibrio de las condiciones de la competencia, y en la mejora de la calidad con la cual los ciudadanos accedieron a sus derechos de participación democrática, a través de una cada vez más sólida posición para enfrentar los actos de presión, inducción o coacción en la emisión del voto ${ }^{20}$ y de referentes más certeros para el ejercicio de un sufragio progresivamente más informado y razonado.

En este sentido, no hay duda que contribuyeron a auspiciar esas condiciones medioambientales aquellas decisiones orientadas a impulsar el voto en libertad y atajar el clientelismo, la compra, coacción, inducción o manipulación del voto, y a favorecer el voto informado y razonado mediante el aseguramiento de la circulación progresivamente más plural de

Cárdenas Gracia, Jaime, “El proceso electoral de 2006 y las reformas electorales necesarias", Cuestiones Constitucionales. Revista Mexicana de Derecho Constitucional, México, núm. 16, enero-junio de 2007, pp. 43-69.

20 Acaso por ello, Sonnleitner, Alvarado y Sánchez sostienen la necesidad de transitar de la "calidad de las elecciones" a la "calidad de los votos". Cfr. Sonnleitner, Willibald et al., "La paradoja mexicana: de la evaluación de la calidad técnica de las elecciones 2012, al debate sobre la calidad del voto y a la cuestión de la legitimidad democrática", Revista Mexicana de Derecho Electoral, México, núm. 4, Especial sobre Observación Electoral 2012, 2013, pp. 379 y 380. 
información electoral y el ajuste a los desequilibrios existentes en la cobertura de las campañas en radio y televisión.

Al efecto, entre 1997 y 2000 , el IFE tomó importantes iniciativas para medir la magnitud de la manipulación del voto durante las elecciones federales, identificar el grado de incidencia en la equidad de la contienda y advertir la gravedad con la que afectan el funcionamiento de la democracia. ${ }^{21}$ A pesar de que dichas prácticas constituyen delitos electorales que se instalan en la órbita de actuación de la Fiscalía Especializada para la Atención de Delitos Electorales (FEPADE), lo cierto es que al ser determinantes para los resultados electorales, el IFE se vio constreñido a involucrase paulatinamente en la construcción de políticas y dinámicas institucionales encaminadas a favorecer el voto razonado y en libertad. ${ }^{22}$

Dentro de las acciones impulsadas por la autoridad electoral debe recordarse la creación, en 1997, de una Comisión del Consejo General encargada de conocer los actos que generaran presión o coacción en el electorado, cuyo acuerdo fue impugnado y revocado por el TEPJF, pero cuya relevancia hizo que fuera retomado para los comicios de 2000 como un mecanismo para promover la participación libre de los ciudadanos en dicho proceso electoral, ordenando el despliegue de acciones para garantizar el ejercicio del sufragio en condiciones democráticas vinculadas con el financiamiento y la fiscalización de los recursos, el diseño e instrumentación de campañas de difusión en medios de comunicación, y el trámite y seguimiento de las denuncias presentadas con motivo de las irregularidades. ${ }^{23}$

21 Cfr. Pozo, Blanca Elena del y Aparicio, Ricardo, Estudio sobre la participación ciudadana y las condiciones del voto libre y secreto en las elecciones federales del año 2000. Una aproximación a la magnitud de la inducción y coacción del voto, México, abril de 2001, en http://www.ine.mx/documentos/DECEYEC/participacion_ciudadana.pdf.

22 Un ilustrativo panorama sobre la compra y coacción del voto se encuentra en Díaz Domínguez, Alejandro y Rivera Loret de Mola, Gustavo, "Fiscalización de los recursos de los partidos políticos en el ámbito federal, 1994-2007”, en Ugalde, Luis Carlos (coord.), Fortalezas y debilidades del sistema electoral mexicano (2000-2012). Ideas para una nueva reforma electoral. La perspectiva estatal e internacional, México, Tribunal Electoral del Poder Judicial de la Federación-Integralia Consultores, 2013, pp. 74 y ss.

23 "Acuerdo del Consejo General del IFE por el que se integra la Comisión del Consejo General para conocer de los actos que generen presión o coacción a los electores, así como de otras faltas administrativas, a petición expresa de los representantes de Partidos Políticos ante el Consejo General", aprobado el 25 de marzo de 1997, y CG175/1999, "Acuerdo del Consejo General del Instituto Federal Electoral por el que se promueve la participación libre de los ciudadanos en el proceso electoral del año 2000", del 17 de diciembre de 1999. Al respecto, Cárdenas Gracia, Jaime et al., Estudios jurídicos en torno al 
En esta línea de acción se inscribe también la promoción de "exhortos" durante los procesos electorales de 1997, 2000 y 2003, para que los gobiernos federal, estatales y municipales suspendieran la difusión de obra pública y programas sociales al interior de las campañas electorales. Es igualmente destacable la convocatoria del IFE para que los partidos políticos y sus candidatos suspendieran sus actos de campaña y de proselitismo durante la "tregua navideña"; es decir, entre el momento de la conclusión de sus precampañas (no reguladas en ese momento) y el inicio formal de las campañas, y la correspondiente invitación a abstenerse, entre otras cosas, de difundir la oferta de gobierno, a lo que proseguiría, tres años más tarde, la suscripción del relevante "Acuerdo de neutralidad" de 2006 en el que se instó a los poderes públicos a evitar la promoción de los servidores públicos, hacer llamados al voto, dejar de asistir a actos partidistas, emitir opiniones a favor de candidatos, aportar recursos públicos a partidos o coaliciones, y condicionar la entrega de apoyos sociales a cambio del voto. ${ }^{24}$

La reforma constitucional de 2007 amplió la cobertura jurídica de las acciones del IFE mediante la obligación de utilizar con imparcialidad los recursos públicos a cargo de los poderes públicos; ${ }^{25}$ a su vez, el Cofipe mantuvo la prohibición expresa - incorporada desde 1990 - de realizar actos dirigidos a generar presión o coacción en el electorado (artículo 4o.) e introdujo como infracción electoral la utilización de programas sociales y recursos del Estado para inducir o coaccionar al electorado a votar a favor o en contra de cualquier partido político o candidato (artículo 347). Bajo esta renovada arquitectura, el IFE emitió normas reglamentarias sobre la imparcialidad en la aplicación de recursos públicos durante las elecciones de 2009 y 2012, y prohibió la utilización de dichos recursos para coaccionar el sufragio o el condicionamiento de la entrega de recursos provenientes de programas sociales. ${ }^{26}$ No debe extrañar que por la relevancia de estas reglas para la emisión de un sufragio libre, genuino y consciente, las fuerzas políticas hayan acometido a su incorporación en la actual LGIPE (artículo 449, inciso e).

Instituto Federal Electoral, México, UNAM, Instituto de Investigaciones Jurídicas, 2000, pp. 160 y ss.

24 Acuerdo CG 39/2006, del 19 de febrero.

25 En torno a los alcances del renovado artículo 134 constitucional, acúdase a Astudillo, César, "El nuevo sistema de comunicación política en la reforma electoral de 2007", en Córdova, Lorenzo y Salazar, Pedro (coords.), Estudios sobre la reforma..., cit., pp. 166 y ss.

26 Acuerdos CG 39/2009, del 29 de enero, y CG 193/2011 del 27 de junio. 
Con el objetivo de impulsar el voto en libertad, conviene subrayar igualmente que desde 2003 el IFE reivindicó su autoridad en la materia al solicitar explícitamente al gobierno federal que se abstuviera de difundir campañas relacionadas con la promoción del voto y la participación ciudadana. ${ }^{27}$ Ello motivó que tres años más tarde pusiera en marcha el programa "Educación para el ejercicio del voto libre y razonado", a través del cual se dio a la tarea de identificar los elementos que condicionan la efectividad de la participación ciudadana, en particular prácticas como la compra y coacción del voto, la carencia de adecuada información electoral y la falta de espacios de discusión colectiva que obstaculizan el ejercicio de un voto razonado, procediendo a desarrollar una estrategia institucional orientada a la generación y fortalecimiento de la conciencia cívica y al ejercicio de los derechos políticos. ${ }^{28}$

Dentro del segundo rubro de acción, y a pesar de que la legislación electoral no ha regulado consistentemente la cobertura informativa de las campañas presidenciales, es dable destacar que desde la elección presidencial de 1994 el IFE se dio a la tarea de expedir normas para fomentar un trato más equitativo en este tramo de la competencia política; entre ellas se destacan los embrionarios "Lineamientos generales aplicables en los noticieros de radio y televisión, respecto de la información o difusión de las actividades de campaña de los partidos políticos" que tuvieron el propósito de equilibrar la cobertura de las campañas en radio y televisión, y que establecieron un inicial contexto de exigencia en la cobertura y difusión de las actividades electorales de los partidos, pero fundamentalmente de los candidatos presidenciales. Meses después estas directrices se harían acompañar de un relevante "exhorto" para que en el ejercicio de su actividad los medios de comunicación proporcionaran información veraz, objetiva, equilibrada, plural y equitativa sobre las campañas electorales. ${ }^{29}$

Para verificar cualitativa y cuantitativamente la cobertura noticiosa de los candidatos y sus partidos, y corroborar el compromiso de los medios

\footnotetext{
27 Acuerdo CG 145/2003, del 25 de junio.

28 Proyecto Institucional "Educación para el ejercicio libre responsable y razonado del voto", México, Instituto Federal Electoral, Dirección Ejecutiva de Capacitación Electoral y Educación Cívica, 2005.

29 Carpizo, Jorge, "Informe que se presenta al Colegio Electoral de la H. Cámara de Diputados del Congreso de la Unión”, Revista Mexicana de Derecho Electoral, México, núm. 2, julio-diciembre de 2012, p. 403. La expedición de dichos lineamientos se ha mantenido dentro de la legislación electoral, ya que se previeron en el Cofipe de 2008 (artículo 49.7) y actualmente se contemplan en la LGIPE (artículo 160.3).
} 
con la cobertura objetiva e imparcial de las contiendas, el IFE impulsó un inicial sistema de monitoreo que con el transcurso de los años fue fundamental para garantizar el principio de equidad en la materia y para dotar al ciudadano de información útil sobre el tratamiento que brindan los noticieros de radio y televisión sobre la información de las precampañas y campañas electorales en el ámbito federal. ${ }^{30}$

En los comicios de 1994 el IFE difundió los resultados de ese embrionario monitoreo, observándose modificaciones sustanciales a la cobertura otorgada a los principales partidos políticos. Como consecuencia de esas acciones preliminares, el monitoreo habría de institucionalizarse dos años después mediante su inclusión en la legislación electoral, ${ }^{31}$ lo que condujo a que la cobertura noticiosa de las elecciones presidenciales de 2000, 2006 y 2012 fuese mucho más apegada a la fuerza electoral de cada partido o coalición, y manejada con mucho mayor equilibrio y objetividad en el contenido de la información. ${ }^{32}$ No puede dejar de destacarse que la autoridad electoral ha ido ensanchando progresivamente el catálogo de espacios informativos a monitorear, pasando de programas eminentemente noticiosos hasta alcanzar paulatinamente trasmisiones de "debate", "de opinión y análisis", e incluso, programas de "revista" y de "espectáculos". ${ }^{33}$

Con todo lo anterior, es notorio que al día de hoy el INE ha ido pavimentando el camino para que al final del día el factor oneroso no sea, en definitiva, el criterio que guíe la sobreexposición pública de un conjunto de candidatos en detrimento de los demás, erigiéndose en un auténtico garante de la paridad de condiciones de la contienda electoral.

30 Es así porque el artículo 76.8 del Cofipe de 2008 incorporó la obligación del IFE de "hacer públicos" los resultados del monitoreo al menos cada 15 días.

31 Fue la reforma electoral de 1996 la que dispuso que la Comisión de Radiodifusión debería realizar "monitoreos muestrales" de los tiempos de transmisión sobre las campañas de los partidos políticos en los espacios noticiosos de los medios de comunicación (artículo 48 del Cofipe). Enseguida, dicha atribución transitaría al Código de 2008 (artículo 76.8) hasta llegar a la actual LGIPE (artículo 185).

32 Esto se destaca en dos estudios serios sobre el particular. Cfr. Guerrero Aguirre, Francisco Javier, El papel de la radio y la televisión en el nuevo modelo de comunicación política: lecciones para México, México, Instituto Electoral del Estado de México, 2013, pp. 312 y ss., especialmente p. 345. También González García, Mónica, "Fiscalización de los recursos de los partidos políticos en el ámbito federal, 2008-2012”, en Ugalde, Luis Carlos (coord.), Fortalezas y debilidades..., cit., pp. 103 y ss.

33 Véase el Acuerdo INE/CG223/2014, del 22 de octubre, donde el Consejo General aprueba el Catálogo de programas de radio y televisión que difunden noticias y la metodología del monitoreo de las transmisiones sobre las precampañas y campañas federales del proceso electoral federal 2014-2015. 


\section{La reorientación de sus exigencias. De ser un árbitro técnico, neutral, discreto y eficaz a constituirse en un actor político fundamental y protagónico del juego democrático}

En sintonía con la interpretación realizada, en su momento inicial el IFE se constituyó en una institución de la democracia formal, en un árbitro al servicio de una organización electoral instrumental al ejercicio del voto popular que poco a poco fue mudando hasta convertirse en una institución que auspicia, protege y favorece las condiciones ambientales por donde discurren las elecciones democráticas.

Este ejercicio de traslación ha sido consecuencia de la reorientación de objetivos impulsada por el propio IFE, en su carácter de "autoridad en la materia" ${ }^{34}$ como lo acabamos de apuntar, pero también de un acuerdo político dirigido a ensanchar progresivamente su capacidad de arbitraje mediante sucesivas reformas a su ámbito de actuación. Las reformas electorales que lo han hecho posible, consideradas integralmente, han incorporado renovadas exigencias que han producido la sobrecarga de su ámbito competencial con potestades cada vez más rigurosas sobre los partidos políticos y sus candidatos, sobre los poderes públicos y sobre un conjunto cada vez más amplio de sujetos que inciden directa e indirectamente en los procesos electorales. ${ }^{35}$

En este sentido, el ciclo de vida del IFE evidenció que uno de los cambios más emblemáticos, por su notoriedad, es el que lo llevó a transitar de un inicial árbitro técnico, neutral, discreto y eficaz a erigirlo en un actor político fundamental y protagónico del juego democrático.

Paradójicamente, a pesar de que la desconfianza de los actores políticos hacia la autoridad electoral — al menos en el discurso- fue manifiesta en sus 23 años de existencia, lo cierto es que cada ajuste a la legislación presupuso la fortaleza institucional del IFE y su capacidad para afrontar

34 No debe pasar desapercibido que el propio IFE ha buscado el redimensionamiento de sus facultades, tal y como se constata en las sugerencias que los consejeros de la integración 1996-2003 formularon al culminar sus encargos, en donde reivindicaron mayores atribuciones en materia de fiscalización y de investigaciones de ilícitos. Córdova Vianello, Lorenzo, "Las razones y el sentido de la reforma electoral de 2007-2008", en id. y Salazar, Pedro (coords.), Estudios sobre la reforma..., cit., pp. 56 y 57.

35 Este modo de proceder ha sido adjetivado de diferentes maneras. Se ha dicho, por ejemplo, que representa una "sobrerregulación". Cfr. Ugalde, Luis Carlos (coord.), Fortalezas y debilidades..., p. 27. 
con éxito el ensanchamiento de su espacio de actuación en la materia. Baste advertir, para constatarlo, que las reformas electorales de $2007 \mathrm{y}$ 2014 se tradujeron en una auténtica eclosión de responsabilidades que confirieron al IFE y al INE, 53 y 74 nuevas atribuciones respectivamente, lo cual no solo exigió un importante reto de implementación, por el alto nivel de complejidad técnica de algunas de ellas, sino que, en conjunto, redimensionaron el perfil político de una institución diseñada para mantener una posición de neutralidad política, y que hoy se ha movido notablemente de ese eje de equilibrio. ${ }^{36}$

En efecto, la institucionalización de un sistema de partidos cada vez más plural y competitivo, la polarización existente entre las fuerzas políticas producto de las tensiones que históricamente han acumulado, la constante comisión de prácticas irregulares e ilegales y las diferentes necesidades propias del contexto político y social de cada elección, han convertido a los procesos electorales en espacios de auténtica lucha por el poder en los que recurrentemente se pone a prueba la capacidad de previsión, reacción, contención, conducción y sanción de la institución electoral.

El contexto político y social en el que se realizaron las elecciones de 1988, 1991 y 1994, propició que la primera gran exigencia que el IFE debió asumir fuera la organización técnica y profesional de las elecciones, con el objetivo de infundir confianza al interior de la clase política y credibilidad frente a la sociedad. Se justifica, por tanto, que la reforma electoral de 1993 haya conferido al IFE la responsabilidad de generar un nuevo padrón electoral y emitir la naciente credencial para votar con fotografía, y que apenas un año más tarde se ordenara la realización de una profunda auditoría al padrón, se promoviera la ampliación del ámbito de observación electoral — de la jornada al entero proceso electoral- y se introdujeran importantes reglas de seguridad en los distintos eslabones en que se articulan los comicios, destacando la producción de boletas foliadas y adheridas a un talón, la limitación de casillas especiales y el número de boletas existentes en cada una e, incluso, la suspensión de la propaganda electoral 10 días antes de la jornada electoral. ${ }^{37}$

36 Véase IFE, Informe General sobre la implementación de la Reforma Electoral, durante el Proceso 2008-2009, México, Instituto Federal Electoral, 2010, pp. 121 y 247. Asimismo, Comisión Temporal de Presupuesto, Informe Anual y Final de Labores Ejercicio 2014, México, INE, 2014, p. 3.

37 Carpizo, Jorge, "Algunos aspectos de la reforma electoral de 1994", Un homenaje a don César Sepúlveda. Escritos jurídicos, México, UNAM, Instituto de Investigaciones Jurídicas, 1995, pp. 63 y ss. 
El avance paulatino del pluralismo político y el aumento de competitividad entre las distintas fuerzas políticas hicieron de la paridad de condiciones en la contienda electoral, la segunda gran exigencia que el IFE debía cumplir. Ello derivó en un ciclo de reformas que se produjeron ante lo incontestable que resultaba que los procesos electorales se llevaran a cabo en entornos cada vez más equitativos, al interior de los cuales la autoridad electoral tenía la responsabilidad de ser generadora y garante al mismo tiempo de la adecuada distribución de un creciente número de prerrogativas a favor de los partidos, y también de la transparencia en cuanto al origen y destino de los recursos por ellos recibidos. ${ }^{38}$

Recordemos que las reformas de 1990, 1993 y 1996 ampliaron paulatinamente las modalidades de financiamiento de la política, y en consonancia con ello, el diseño institucional confió a la autoridad electoral la responsabilidad de conducir el impacto del factor oneroso al interior de las campañas. Como resultado, el IFE se vio investido de facultades para la equitativa distribución de los montos de financiamiento público, pero también de mecanismos para la eficaz vigilancia de los límites, las prohibiciones al financiamiento privado y los topes de gastos de campaña, a través de un esquema de fiscalización del origen y destino de los recursos partidistas cada vez más oportuno, omnicomprensivo, abigarrado y profesional que tuvo en la Comisión de Fiscalización, creada en 1996, uno de sus referentes más destacados. ${ }^{39}$

En ese mismo sentido, las reformas de 1996 y 2007 confirieron una exposición pública creciente a los partidos políticos en la radio y la televisión, propiciando la regulación de un financiamiento público indirecto que con el paso del tiempo implicó un esfuerzo institucional inusitado. En 1996, las reglas electorales permitieron el uso de los tiempos del Estado para fines electorales a través de un esquema de programas de dis-

38 La reconstrucción del ciclo de reformas que permite advertir que el tema de las "condiciones de la competencia política" fue uno de los más relevantes en cada una de las discusiones se encuentra en Woldenberg, José, La mecánica del cambio..., cit., pp. 363 y ss. Una lectura en perspectiva de los cambios suscitados en 20 años se encuentra en Morales Manzanares, Rodrigo, "Dinero y partidos: algunos dilemas ineludibles", Instituto Federal Electoral 20 años..., cit., pp. 113 y ss.

39 Córdova Vianello, Lorenzo, "El financiamiento de los partidos políticos en México", en Gutiérrez, Pablo y Zovatto, Daniel (coords.), Financiamiento de los partidos políticos en América Latina, México, Instituto Internacional para la Democracia y la Asistencia Electoral-Organización de los Estados Americanos-UNAM, 2011, pp. 354 y ss.; Agíss Bitar, Fernando, "Fiscalización de los recursos de los partidos políticos. Una reflexión sobre la aplicación efectiva de las normas de fiscalización", Temas selectos de derecho electoral, México, Tribunal Electoral del Poder Judicial de la Federación, núm. 1, 2010. 
tinto formato y duración que se acompañaba de spots electorales que el IFE debía adquirir y distribuir de forma equitativa entre los partidos y las coaliciones, con independencia de los promocionales que los mismos podían contratar de manera directa con los medios de comunicación.

En 2007 se produjo un auténtico giro copernicano en este rubro con la edificación de un nuevo sistema de comunicación político-electoral caracterizado por la instauración de una modalidad plenamente gratuita del acceso de los partidos políticos a la radio y la televisión, la prohibición tajante a la contratación de propaganda electoral, el establecimiento de restricciones al contenido de los mensajes políticos, la reconfiguración del régimen de sanciones frente a las infracciones cometidas en la materia y el no menos relevante monopolio del IFE en la administración del nuevo modelo. ${ }^{40}$ A partir de este ajuste, el IFE se erigió en autoridad única para la asignación de los tiempos del Estado en la materia y para distribuir los tiempos que corresponden a los partidos políticos y a las coaliciones tanto en elecciones federales como locales, dentro del periodo electoral y fuera de él, en las precampañas y campañas e, incluso, de aquellos espacios que correspondan a las autoridades electorales administrativas $y$ jurisdiccionales en los ámbitos federal y local, respectivamente.

De forma adicional, la reforma exigió a la autoridad electoral una vigilancia estricta para inhibir la contratación de espacios adicionales, no solo de spots, sino de entrevistas, cobertura noticiosa, propaganda camuflada, publicidad integrada, infomerciales, así como un mayor activismo para frenar las campañas denigratorias, impedir los mensajes con contenido calumnioso hacia las personas, o determinar el margen de licitud de los informes parlamentarios y de gobierno, todo lo cual terminó posicionando al IFE como autoridad delimitadora de la libertad de expresión. ${ }^{41}$

40 Respecto a los alcances de este cambio, Astudillo, César, "El nuevo sistema de comunicación política...", cit., pp. 131 y 132. Con énfasis en las repercusiones de dicho modelo para la fluidez de la comunicación política véase Astudillo, César, "La libertad de expresión en el contexto del modelo de comunicación político electoral", Revista Mexicana de Derecho Electoral, México, núm. 3, enero-junio de 2013, pp. 3-41.

41 Sobre estos tópicos hay una abundante doctrina, entre la que destaca Carbonell, Miguel, "La libertad de expresión en materia electoral", Temas selectos..., cit., núm. 3, 2010; Temkin Yedwab, Benjamín y Salazar Elena, Rodrigo, "Libertad de expresión y campañas negativas", Temas selectos..., cit., núm. 12, 2010; Roldán Xopa, José, "La libertad de expresión y equidad. ¿La Constitución contra sí misma?”, Temas selectos..., cit., núm. 20, 2011; Buendía Hegewisch, José y Azpiroz Bravo, José Manuel, "Medios de comunicación y la reforma electoral 2007-2008. Un balance preliminar”, Temas selectos..., cit., núm. 26, 2013; Chacón Rojas, Oswaldo, "Informe de labores de funcionarios públicos y la garantía de equidad en las contiendas", Temas selectos..., cit., núm. 33, 2013; Baños Martínez, 
La necesidad de que ningún factor externo al proceso electoral contara con la capacidad de condicionar sus resultados motivó que los "actores no autorizados" se transformaran en "entes regulados", y que la contención de sus influjos se convirtiera en la tercera gran exigencia que la autoridad electoral debía afrontar. Si bien la reforma de 1996 intentó dar pasos hacia adelante al establecer un inicial catálogo de sanciones, lo acontecido en la elección presidencial de 2006 patentizó la necesidad de articular sólidos obstáculos ante cualquier injerencia indebida de frente a la equidad de los comicios. ${ }^{42}$

La reforma político electoral de 2007 confirió al IFE una relevante atribución para verificar el respeto de los concesionarios y permisionarios de los medios de comunicación hacia las pautas ordenadas por él, a través de un monitoreo que permitiera confirmar su adecuada difusión y, sobre todo, el respeto a la prohibición explícita de contratación de spots adicionales en la radio y la televisión. ${ }^{43}$ Asimismo, le otorgó la responsabilidad de vigilar la propaganda institucional proveniente de los distintos niveles de gobierno, poderes públicos, fracciones legislativas y representantes populares, con el objeto de verificar si su difusión se constreñía al ámbito temporal y geográfico dispuesto para ello, o si se respetaban las excepciones permitidas a la propaganda con fines informativos, pero sobre todo, con la finalidad de impedir que a través de ella se realizara la promoción personalizada de servidores públicos, atajando así los riesgos que su indebida influencia pudiera producir en las preferencias electorales de los ciudadanos. ${ }^{44}$

Marco Antonio y Carriedo, Luis Miguel, “Distorsiones de la propaganda política”, Justicia Electoral, Revista del Tribunal Electoral del Poder Judicial de la Federación, México, Cuarta Época, vol. 1, núm. 5, 2010.

42 En relación con los acontecimientos que motivaron la reforma de 2007, véase a Salazar Ugarte, Pedro, "La reforma constitucional: una apuesta ambiciosa" y Córdova Vianello, Lorenzo, "Las razones y el sentido de la Reforma Electoral de 2007-2008", ambos en Córdova Vianello, Lorenzo y Salazar, Pedro (coords.), Estudios sobre la reforma..., cit.

${ }^{43}$ Guerrero Aguirre, Francisco Javier, El papel de la radio y la televisión..., cit., pp. 78-86.

$44 \mathrm{Al}$ respecto, acúdase a "Propaganda gubernamental. Excepciones durante un periodo de campaña. Expediente SUP-RAP-54/2012 y acumulados”, Diálogos judiciales. Versiones estenográficas, México, núm. 3, Tribunal Electoral del Poder Judicial de la Federación, 2014; Villa Berger, Patricia, "Propaganda gubernamental durante campañas electorales”, Serie comentarios a las sentencias..., cit., núm. 45, 2012; Sánchez Muñoz, Oscar, "Propaganda gubernamental y elecciones", Serie comentarios a las sentencias... op. cit., núm. 54, 2013; Murayama Rendón, Ciro, "Publicidad gubernamental y campañas electorales locales. Los mensajes del presidente Felipe Calderón en 2010", Serie co- 
La misma reforma de 2007 otorgó atribuciones al IFE para proceder a la contención de actos anticipados de precampaña y campaña, con el propósito de impedir que quienes luchan por la obtención de una candidatura partidista o por un puesto de representación popular, obtengan una ventaja ilícita respecto a sus competidores. Con ello, se amplió su capacidad de verificación del cumplimiento de las reglas sobre ingresos y gastos de precampaña, y al mismo tiempo, su potestad de gestión sobre los spots electorales de esta fase del proceso electoral. ${ }^{45}$

La pretensión cada vez más evidente de que la autoridad electoral se encargase de procurar el respeto al principio de equidad, en su calidad de eje rector de la nueva etapa de nuestra evolución democrática, puso nuevas y más sensibles exigencias sobre la institución, haciendo que paulatinamente tuviera una intervención más activa e incisiva en temas tan complejos como significativos para la dinámica comicial.

Destaca, por ejemplo, la solicitud que recurrentemente se ha formulado a la institución con relación a la utilización de los programas sociales con fines electorales, para disuadir el ejercicio parcial de los recursos públicos y detener la intención de granjearse a través de ellos, o de propaganda electoral construida en torno a ellos, la adhesión política de los ciudadanos. ${ }^{46}$

La vigilancia que se le ha exigido para impedir la entrada de recursos de procedencia ilícita, sobre todo del narcotráfico y la delincuencia organizada, al ámbito de las campañas electorales, y su más decidida intervención en el blindaje de las candidaturas, con el propósito de verificar que los contendientes no tengan antecedentes criminales, y disuadir de alguna manera el riesgo que para el Estado supone que el crimen organizado tenga injerencia en la vida pública del país a través del vínculo generado por el financiamiento de las campañas o los antecedentes criminales de algún aspirante. ${ }^{47}$

La mayor incisividad que se le ha reclamado respecto de los parámetros a los que deben conformarse las empresas que realizan encuestas

mentarios a las sentencias..., cit., núm. 52, 2013; Martínez Espinosa, Roberto, "Artículo 134 constitucional y su interpretación judicial electoral en México", Temas selectos..., cit., núm. 44, 2014.

45 Véase Tapia, Cecilia, "Regulación del proceso electoral”, en Córdova Vianello, Lorenzo y Salazar Ugarte, Pedro (coords.), Estudios sobre la reforma..., cit., pp. 380 y ss.

46 Rábago Dorbecker, Miguel, "La propaganda sobre programas sociales como acto de campaña”, Serie comentarios a las sentencias... op. cit., núm. 35, 2013.

47 Chacón Rojas, Oswaldo, Dinero del crimen organizado y fiscalización electoral, México, Fontamara, 2011, pp. 137 y ss. 
electorales y sondeos de opinión, bajo la intención de modular la influencia distorsionadora que su actividad puede generar en las preferencias de los ciudadanos. ${ }^{48}$

Incluso, la intervención más decidida que se le ha requerido en el manejo de la publicidad oficial que realizan las dependencias públicas de los tres niveles de gobierno, para procurar que los mensajes que difundan los medios de comunicación oficiales no constituyan propaganda electoral prohibida por la Constitución, o bien, para que la contratación de publicidad con las empresas del sector no derive en la indebida cobertura informativa de determinadas campañas políticas en detrimento de las demás. ${ }^{49}$

Finalmente, la colaboración solicitada al IFE, y ahora mismo al INE para que gestione ante las instancias competentes las condiciones de seguridad requeridas por partidos políticos y candidatos, en aquellos ámbitos de la geografía electoral que presentan elevados índices de inseguridad, con el objetivo de que puedan realizar actos de campaña bajo medidas de protección que garanticen su integridad personal.

Todas estas exigencias han puesto a la autoridad electoral frente a un nuevo contexto de actuación institucional, al que se ha llegado con motivo de ajustes formales pero también de necesidades reales afrontadas por el propio IFE, o en muchas ocasiones requeridas por los propios actores políticos en función de hechos coyunturales, y que implicaban una capacidad de arbitraje con mucho mayor especificidad. La metamorfosis producida obligó a procesar con discreción y eficacia aquellos problemas iniciales que por ser "típicos" de la organización electoral así lo ameritaban; sin embargo, al final de su ciclo de vida institucional el IFE había experimentado un cambio de tal magnitud que en los hechos lo había constreñido a ejercer un rol sustancialmente distinto y de gran

48 Desde el comienzo de su andadura, el IFE incentivó la publicación de encuestas como mecanismo para disuadir acciones de fraude electoral. Las encuestas quedaron reguladas en el Cofipe de 1996 (artículo 190.4, 190.5) y de 2008 (artículo 237.7), y se recogieron en la LGIPE de 2014 (artículo 213.1) a través de una amplia atribución que dejó en manos del Consejo General del INE la emisión de "reglas, lineamientos y criterios" que las personas físicas o morales deberán adoptar para realizar encuestas o sondeos de opinión tanto en los procesos electorales federales como locales. Véase Estrada Utraffon, Luis, "Regulación de encuestas pre-electorales y de salida en perspectiva comparada", en Ugalde, Luis Carlos (coord.), Fortalezas y debilidades..., cit., p. 362.

49 Ugalde, Luis Carlos, "Combatir la enfermedad, no los síntomas: tres propuestas para atacar el costo creciente de las campañas electorales en México”, Revista Mexicana de Derecho Electoral, cit., núm. 3, p. 493. 
activismo, sobre todo en aquellos casos que por su "atipicidad" presuponían una mayor capacidad de implicación, interlocución y protagonismo político, lo cual, en perspectiva histórica, terminó por convertir al IFE en un actor esencial, protagónico y cada vez más visible del proceso democrático.

V. El viraje de sus fines. De ser una institución para la transición política a convertirse en pieza clave de la consolidación democrática

No hay duda que en sus inicios el IFE se concibió como una institución de y para la transición política. Su surgimiento como autoridad en la materia fue resultado del aceleramiento del cambio político experimentado en 1988, que tuvo en la creación de la autoridad electoral una de las respuestas más significativas para hacer de la reforma electoral la vía privilegiada para la democratización del país.

El IFE nació como un organismo bajo cuya supervisión y arbitraje tendría que transformarse el régimen político, con el objeto de transitar de un sistema caracterizado por la presencia hegemónica de un partido a un régimen asentado en las premisas del pluralismo democrático. En consecuencia, no debe extrañar que uno de los fines que le fueron asignados por el naciente Cofipe de 1990, haya sido precisamente "contribuir al desarrollo de la vida democrática”, posicionándose desde sus orígenes como un actor fundamental de la transición política, lo cual, en perspectiva histórica, terminaría por convertirlo en pieza clave para calibrar la salud del sistema democrático, sin cuya participación institucional no se concibe la alternancia, la transición política ni el proceso de consolidación democrática que vive el país. ${ }^{50}$

Si se observa retrospectivamente el contexto en el que el IFE surgió a la vida institucional se podrá constatar con facilidad una realidad política en la cual un solo partido tenía la capacidad de dominar todos los extremos de la representación popular y la vida pública, en la que sencillamente no existía un sistema de partidos, sino partidos que luchaban por mantenerse con vida, aunque ello dependiera de sus vínculos con el partido hegemónico, y donde el incipiente pluralismo no era suficiente

50 No se cumplía un año de su andadura cuando Colomer reconocía que el escenario clave de la democratización de los procesos electorales había sido el IFE. Colomer, Josep María, "México: Una democracia a medias", Revista Claves, Madrid, núm. 87, 1998, p. 47. 
para consolidar una oposición numéricamente más amplia pero política e institucionalmente aún debilitada. ${ }^{51}$

Las elecciones se consideraban meros ejercicios de legitimación del poder, y la voluntad popular expresada mediante el sufragio representaba un ejercicio recurrente al que concurrían los ciudadanos sin las más elementales garantías de que su voto sería contado y de que sería eficaz al momento de configurar la representación política.

El andamiaje electoral lejos estaba de ofrecer condiciones mínimamente razonables para una equilibrada competencia, o de albergar instrumentos dirigidos a crear confianza y credibilidad en los resultados -no existía, por ejemplo, un padrón confiable, listas nominales, ni mucho menos una credencial para votar con fotografía-. Como corolario de lo anterior, el edificio electoral se encontraba coronado por instituciones ancladas en la órbita del gobierno, cuyas decisiones se tomaban bajo criterios políticos, en donde la autocalificación política de las elecciones terminaba por infundir aún más desconfianza al procesamiento de los resultados electorales y por ensanchar la carencia de legitimidad del sistema político.

Los cambios electorales instrumentados a partir de tres grandes generaciones de reformas se orientaron a disponer la cobertura jurídica para transitar hacia una realidad distinta que, en perspectiva, ha hecho posible el enraizamiento de un pluralismo político consecuencia de una par conditio en la competencia que en el mediano plazo ha alcanzado todos los extremos de la dinámica electoral. La organización de los comicios, por su parte, ha experimentado una evolución sin precedentes que ha logrado consolidar un conjunto de estándares que aseguran eficacia, rigor técnico y confiablidad, producto del profesionalismo acumulado a partir del desempeño autónomo e independiente de la autoridad electoral dentro de ocho procesos electorales federales. La reivindicación del sufragio, en este sentido, ha logrado asentarse como el único elemento legitimador del poder público, resultado de un lento pero constante esfuerzo por restablecer la confianza entre la ciudadanía y las elecciones, a partir de la

51 Una lectura de las condiciones políticas que precedieron a la creación del IFE se encuentra, respectivamente en Valdés Zurita, Leonardo, "Pluralismo y reformas electorales: los motores del cambio político en México"; Gómez Tagle, Silvia, "Del partido hegemónico al pluralismo político en México: ¿hacia un nuevo sistema de partidos?”, y Baños Martínez, Marco Antonio, "El IFE: palanca de cambio político en México", todos en Instituto Federal Electoral 20 años..., cit., pp. 14-35, 68-111, y 224-307, respectivamente. 
articulación de comicios verdaderamente creíbles y con todas las garantías de regularidad jurídica. ${ }^{52}$

El avance obtenido en el ámbito de la democracia formal, de la mano del redimensionamiento del IFE como auténtica autoridad en materia electoral generó que al final de su ciclo institucional, más que hablar de la organización de procesos electorales se haya enfatizado en la exigencia de organizar elecciones con los mayores estándares de calidad. Acaso por ello, la "calidad de las elecciones" se ha situado como idea clave para garantizar que el ejercicio de los derechos político-electorales se lleve a cabo en circunstancias cada vez más homogéneas a partir de la estandarización de procedimientos, la nivelación de autoridades electorales, el equilibrio de las condiciones de la competencia, la homologación de dinámicas institucionales y el escrupuloso cumplimiento de los principios constitucionales que rigen las elecciones. ${ }^{53} \mathrm{~A}$ este propósito ha servido, sin asomo de duda, la nacionalización de la función electoral, la estandarización de reglas y la homologación de procedimientos derivado de la reforma constitucional de febrero de $2014 .^{54}$

En el ecuador de su recorrido institucional —el año 2000_, más allá de advertir el alcance de su afinado despliegue operativo a favor de la

52 Los efectos de algunas de estas reformas las hemos analizado en Astudillo, César, "El modelo de organización electoral en México", en id. y Carpizo, Jorge (coords.), Constitucionalismo. Dos siglos de su nacimiento..., cit., pp. 758 y ss. Baños explica la contribución del IFE a la vida democrática del país a partir de su caracterización como árbitro independiente e imparcial, la conexión entre la ciudadanía y las elecciones, la generación de competencias electorales justas y con un arbitraje equitativo y transparente, la instrumentación de condiciones de confianza para el ejercicio libre del sufragio, y la credibilidad y legitimidad en la proclamación de los elegidos. Baños Martínez, Marco Antonio, "El IFE: palanca de cambio político en México", Instituto Federal Electoral 20 años..., cit., pp. 224-307.

53 En torno a la calidad de las elecciones en el espacio estatal, acúdase a Méndez, Irma y Loza, Nicolás (coords.), La calidad de las elecciones sub nacionales en México, México, Flacso-PNUD, 2011.

54 Como apunta Córdova Vianello: "Claramente la reforma electoral concibió la idea de una autoridad electoral que debe garantizar los mismos parámetros de aplicación de las leyes por parte de las autoridades locales. De ahí que la estandarización de las elecciones, la homogeneidad de criterios y procedimientos, y la distribución entreverada de competencias entre el INE y los OPLEs sea el sustento de una nueva etapa de colaboración institucional que contribuya a hacer más transparente y equitativa la democracia mexicana", Córdova Vianello, Lorenzo, "Complejidad y novedades", Revista Voz y Voto, núm. 260, México, octubre de 2014, pp. 6-9. Sobre algunas implicaciones de la nacionalización de elecciones y los retos de la renovada autoridad electoral, acúdase a las reflexiones compiladas en Astudillo, César, Instituciones electorales nacionales..., cit. 
emisión del voto ciudadano, el IFE priorizó la generación de una política de educación cívica y cultura política para incentivar que quienes concurrieran a las urnas lo hicieran mediante un voto cada vez más consciente, informado y razonado. Con este propósito se dio a la tarea de advertir dónde se han encontrado los mayores obstáculos para el ejercicio de los derechos y quiénes han sido los sectores más afectados con la finalidad de que el diagnóstico permitiera la puesta en marcha de estrategias específicas dirigidas a universos sociales determinados (niños, jóvenes, mujeres, adultos...) cuya implementación coadyuvase progresivamente a generar confianza en la participación ciudadana, a fomentar la cultura democrática, y al final de día, a construir una ciudadanía plenamente inspirada en los valores democráticos. ${ }^{55}$

El esfuerzo realizado durante más de una década sería retomado con fuerza casi al finalizar el ciclo de vida institucional del IFE con la consecución de una auténtica política de Estado en materia de educación cívica que se materializó en la Estrategia Nacional de Educación Cívica para el Desarrollo de la Cultura Política Democrática en México 2011-2015, entre cuyos propósitos se encuentra la medición de la "calidad de la ciudadanía" a partir del conocimiento de los valores democráticos, los derechos reconocidos a las personas, y sobre todo, los incentivos y obstáculos que favorecen o dificultan su pleno ejercicio en democracia, con el propósito de articular esfuerzos con otras instituciones del Estado responsables en la materia, para generar políticas que contribuyan a hacer efectiva la igualdad sustancial que subyace al orden democrático en beneficio de una participación ciudadana más robusta y de un cambio cultural verdadero. ${ }^{56}$

A pesar de lo anterior, no hay duda que el mayor reto de la institución electoral pasa por reconocer y advertir que las disfuncionalidades de nuestro sistema democrático no obtendrán su oportuna corrección en

55 Peschard divide en tres etapas los esfuerzos institucionales del IFE a favor de la educación cívica. Los primeros pasos abarcan 1990 a 1997; la etapa de planeación para la educación cívica se establece entre 1997 y 2003, donde se aprueba el Plan Trianual de Educación Cívica 2000-2003; la etapa de consolidación y nuevos horizontes, entre 2003 y 2009, que dio como resultado el Programa Estratégico de Educación Cívica 2005-2010. Cfr. Instituto Federal Electoral 20 años..., cit., pp. 343 y ss. En general, acúdase a Woldenberg, José, El cambio democrático y la educación cívica en México, México, Cal y Arena, 2007.

56 Informe país sobre la calidad de la ciudadanía en México, México, IFE-Colmex, 2014, pp. 19 y ss.; Córdova Vianello, Lorenzo, "Desafíos para la consolidación del INE y del modelo nacional de elecciones", Voz y Voto, in fine. 
el terreno específicamente electoral, ya que derivan de las falencias de un sistema de bienestar que históricamente ha dado muestras de su incapacidad para otorgar los insumos mínimos para que las personas accedan a una vida digna a través de la adecuada satisfacción de sus necesidades básicas de alimentación, salud, educación, trabajo, vivienda, seguridad social, etcétera.

A la autoridad electoral no le corresponde incidir directamente en el campo de la democracia sustancial, ya que esa responsabilidad pertenece a lo órbita de actuación de los poderes públicos del Estado; ${ }^{57}$ sin embargo, la autoridad electoral ha sido plenamente consciente de la realidad y ha venido señalando cada vez con mayor insistencia las negativas repercusiones de dichas disfuncionalidades en el crecimiento de la participación ciudadana, en los niveles de estima social hacia los partidos políticos y la clase gobernante, en la comprensión de la relevancia de las elecciones y, en definitiva, en la valoración de nuestra democracia. En lo que se ha empeñado con rigor, es en subrayar que solo a través de una participación ciudadana robusta y portadora de auténticas credenciales democráticas se generaran las condiciones para influir decididamente en las grandes decisiones que orientan el rumbo del Estado.

Como puede apreciarse, al final de su ciclo, más que ser un órgano de la democracia formal, el IFE se convirtió en una institución que auspicia, procura y promueve las condiciones ambientales de las elecciones democráticas. A lo largo de estas décadas ha dejado de concebirse como un órgano vinculado al cumplimiento de la ley para erigirse en una instancia que favorece, en el contexto de sus atribuciones, la realización de los valores democráticos auspiciados por nuestra carta magna. Por ende, no representa ya una estructura a favor de la simple organización de los comicios, sino una instancia que participa decididamente en la corrección de los defectos de la democracia electoral y en la enunciación de las disfuncionalidades de la democracia sustancial.

No hay duda que el IFE, en el pasado, y el INE en el espacio temporal del presente, representan un andamiaje institucional orientado permanentemente a garantizar la calidad de las elecciones, auspiciar la calidad del voto y alentar la calidad de la ciudadanía en beneficio de la salud del sistema democrático.

57 Como señala Baños, “El IFE no es una "varita mágica” y por eso no se puede esperar de esta institución que cambie el panorama de desigualdad que lamentablemente aún priva en nuestro país..., Instituto Federal Electoral 20 años..., cit., p. 297. 


\section{El redimensionamiento de la autoridad electoral. De un alcance exclusivamente federal a una auténtica dimensión nacional}

El IFE nació a la vida institucional como un organismo público al que la Constitución expresamente le confirió la "organización de las elecciones federales". La decisión entonces tomada fue consecuente con la directriz auspiciada en la reforma electoral de 1946, que compatibilizó el nuevo modelo de organización electoral con la naturaleza del Estado federal mexicano. La nueva institucionalidad electoral se hizo compatible con el modelo de organización territorial, dando como resultado la existencia de una competencia electoral federal y de su correspondiente competencia estatal que dejó en manos de los estados de la República y el Distrito Federal la organización de sus propias elecciones. Producto de lo anterior, como lo hemos sostenido en otra parte,

se institucionalizó... otra de las características del modelo: las elecciones no habrían de gestionarse por un único órgano electoral, ni controlarse por un único tribunal, sino por un abigarrado conjunto de instituciones, de conformidad con el tipo y el ámbito de cada elección. ${ }^{58}$

Ahora bien, visto en retrospectiva, al finalizar su ciclo de vida, la autoridad electoral había dejado de tener un alcance exclusivamente federal producto de una tendencia centralizadora de ámbitos de actuación que progresivamente lo fueron convirtiendo en una autoridad electoral de carácter nacional, y cuya caracterización definitiva adquiriría plena carta de naturalización con la reforma electoral de 2014 y la transformación del IFE en INE.

Al efecto, recordemos que el padrón electoral, el registro de electores y la credencial para votar, configuraron desde su origen competencias de alcance nacional que se otorgaron a la entonces Comisión Electoral. ${ }^{59} \mathrm{No}$ obstante, la entrada en vigor de la reforma de 1990 propició que la fun-

58 Astudillo, César, "El modelo de organización electoral en México", en id. y Carpizo, Jorge (coords.), Constitucionalismo. Dos siglos de su nacimiento..., cit., p. 762.

59 Así lo estableció la Ley Federal Electoral de 1946; la Ley Electoral de 1951, la Ley de Organizaciones Políticas y Procesos Electorales de 1977 y el Código Federal Electoral de 1987 mantendrían la competencia nacional de la autoridad electoral en la materia. Cfr. Patiño Camarena, Javier, Nuevo derecho electoral mexicano, México, Constitucionalista-IFE, 1999, pp. 86 y ss. 
ción electoral se asentara en dos planos de actuación, el federal y el local, a través de un diseño institucional que los hacía coexistir armónicamente con base en un sistema de competencias exclusivas y excluyentes que permitían, al menos inicial y teóricamente, que cada ámbito mantuviera idénticas competencias para la organización de sus elecciones. Así, por ejemplo, al IFE le correspondió la organización del Registro Federal de Electores - artículo 92 del Cofipe de 1990- con lo cual la generación del catálogo de electores y sus derivados pasó a considerarse una competencia "dual" que podía compartirse entre la federación y los estados. Eso motivó que en 1992 el estado de Baja California procediera a la creación de sus propios instrumentos de identificación electoral con la primera credencial para votar con fotografía, que un par de años más tarde sería fuente de inspiración para la credencial de elector empleada en las elecciones federales de $1994 .^{60}$

Prever que dicha credencial podría ser utilizada como documento de identificación del ciudadano en la realización de diversos trámites ante instituciones públicas y privadas, generó el rápido desplazamiento de cualquier otro documento de identificación. A su vez, el imponente despliegue operativo para integrar el registro de electores - catálogo de electores y padrón electoral- para verificarlo, actualizarlo y vigilarlo, generar las listas nominales de electores y expedir la credencial para votar con fotografía, dejó rápidamente en claro la necesidad de concentrar este esfuerzo institucional en una sola autoridad, el IFE, y evitar con ello duplicidades y gastos innecesarios. Con lo anterior se produjo el primer elemento de marcado carácter nacional a favor de una autoridad electoral de naturaleza federal.

El segundo paso hacia la nacionalización de competencias fue resultado de la reforma electoral de 2007. Dicha modificación confirió al IFE el monopolio tanto de la administración del nuevo modelo de comunicación político-electoral como del acceso a la información bancaria, fiduciaria y fiscal de los partidos políticos, y abrió la posibilidad de centralizar la organización de las elecciones de toda la República en la misma autoridad. ${ }^{61}$

60 Astudillo, César y Córdova Vianello, Lorenzo, Los árbitros de las elecciones estatales. Una radiografía de su arquitectura institucional, México, Instituto Electoral y de Participación Ciudadana del Estado de Jalisco-UNAM, Instituto de Investigaciones Jurídicas, 2010, nota 34, p. 13.

${ }^{61}$ Sobre el nuevo modelo de comunicación política, acúdase a las referencias señaladas en el punto II de este artículo. El debate en torno a la federalización o centralización de la organización de los comicios estatales, se encuentra referido en ibidem, pp. 14 y ss. 
Con dicha reforma todo lo concerniente a la administración de los tiempos del Estado a nivel nacional, tanto en radio como en televisión quedó en manos del IFE, y cualquier solicitud de alguna instancia fiscalizadora de las entidades federativas necesitaba pasar por el filtro de la Unidad de Fiscalización de los Recursos de los Partidos Políticos, lo que terminó por erigirlo en la única autoridad electoral de la República con atribuciones para trascender los secretos que protegen dicha información. ${ }^{62}$

La misma reforma encaminó el tercer paso en la misma dirección al abrirse - aunque en los hechos no ocurrió- a la asunción federal de la competencia electoral estatal, justificada en la necesidad de "aprovechar las capacidades materiales y humanas de que el IFE dispone a lo largo y ancho del territorio nacional", a efecto de que en el corto y mediano plazo, se acometiera a la reducción de costos y al aumento de la eficiencia y confiabilidad con que se organizan los procesos electorales en el ámbito estatal. ${ }^{63}$

Las modificaciones del movimiento centralizador al que se ha hecho referencia hicieron que el IFE, en sus más de 23 años de existencia, haya dejado de ser una institución federal para erigirse cada vez con mayor nitidez en una instancia con marcados ingredientes nacionales, que en el ocaso de su ciclo de vida institucional aparecía con el monopolio de insumos básicos para la organización electoral como el padrón electoral, la administración del acceso a la radio y la televisión de los partidos políticos y las instituciones electorales, y el acceso a la información bancaria, fiduciaria y fiscal, todo ello aderezado por una competencia centralizadora que le permitía, bajo petición expresa, asumir la completa función electoral en alguna entidad federativa del país. ${ }^{64}$

El arreglo institucional descrito tuvo en la reforma electoral de febrero de 2014 un ajuste de proporciones mayúsculas, producto de la exacerbación competencial del recién inaugurado Instituto Nacional Electoral como consecuencia del diseño de un modelo orientado a impulsar un

62 Véase Córdova, Lorenzo, "El financiamiento de los partidos políticos en México", en Gutiérrez, Pablo y Zovatto, Daniel (coords.), El financiamiento de los partidos políticos en América Latina, México, IDEA Internacional-OEA-UNAM, Instituto de Investigaciones Jurídicas, 2011, p. 367.

${ }^{63}$ Así se establece en la propia exposición de motivos de la reforma a diversos artículos de la Constitución, publicada en el Diario oficial de la Federación el 13 de noviembre de 2007.

64 Astudillo, César, "El Instituto Nacional de Elecciones en el contexto del modelo de organización electoral”, en Astudillo, César, Instituciones electorales nacionales..., cit., pp. 49 y 50 . 
"sistema nacional de elecciones"65 caracterizado por la coexistencia de una autoridad de carácter nacional y un conjunto de organismos públicos locales electorales (OPLE) que mantienen inicialmente la organización de sus respectivas elecciones pero que, en el extremo, pueden verse privados total o parcialmente de sus competencias a partir de una distribución competencial altamente ambigua que ha necesitado de una incesante labor definidora a través de reglamentos, bases, lineamientos y directrices surgidas a partir del ensanchamiento de la potestad reglamentaria del renovado Consejo General del INE. ${ }^{66}$

Lo más representativo de la más reciente reforma constitucional es que ha dado lugar al nacimiento de una competencia originaria a favor del INE sobre los procesos electorales de todo el país, lo cual representa un punto de inflexión respecto a las directrices del modelo precedente. Dicha competencia originaria le concede capacidad de decisión plena en materias tan elementales como la capacitación electoral, geografía electoral, padrón y lista de electores, organización electoral, resultados preliminares, encuestas, sondeos, conteos rápidos, observación electoral, materiales electorales y fiscalización, tanto en los comicios federales como en los locales, cuando en el arreglo precedente, con excepción del padrón y lista de electores, dichos rubros eran competencias propias y exclusivas de cada autoridad electoral en su correspondiente ámbito de actuación. ${ }^{67}$

Derivado de la regulación de la reforma, las leyes generales han convertido esa original competencia centralizada del INE en competencias descentralizadas en lo concerniente a los procesos electorales locales. De conformidad con la forma en que las mismas pueden ejercerse configuran competencias delegadas, delegables e indelegables; así, por ejemplo, todo lo relacionado con la capacitación electoral, la ubicación de las casillas y la designación de funcionarios de la mesa directiva de casilla de las elecciones locales, constituyen competencias delegadas por mandato constitucional y legal a favor de los OPLE, pero que el INE en cualquier momento puede reasumir (transitorios octavo de la Constitución y décimo segundo de la LGIPE); ${ }^{68}$ en cambio, lo relativo a la fiscalización de

65 INE, La reforma electoral en marcha. Avances en la instrumentación y perspectivas para el proceso electoral 2014-2015, México, Instituto Nacional Electoral, 2014, p. 7.

66 Sobre la potestad reglamentaria del IFE, véase Jiménez Dorantes, Manuel, Capacidad normativa y autonomía de los órganos electorales. El caso del IFE, México, Tribunal Electoral del Poder Judicial de la Federación, 2010.

67 Astudillo, César, "El esquema competencia del nuevo Instituto Nacional Electoral”, Revista Letras para la Democracia, México, núm. 3, agosto de 2014, pp. 17-21.

68 Derivado del Acuerdo INE/CG100/2014, del 14 de julio, el Consejo General de- 
los ingresos y egresos de los partidos y candidatos, representa una competencia delegable siempre que medie acuerdo del Consejo General del INE; ${ }^{69}$ finalmente, la gestión del Servicio Profesional Electoral Nacional representa una competencia indelegable que se deposita exclusivamente en manos de la autoridad nacional. ${ }^{70}$

A pesar de lo anterior, del modelo previo permaneció la distinción de competencias exclusivas y excluyentes a cargo del INE sobre las elecciones federales y competencias exclusivas y excluyentes de los OPLE sobre los comicios estatales. ${ }^{71}$

Con la finalidad de salvaguardar la unidad y coherencia del sistema nacional de elecciones, y de proveer la estandarización de las actividades que se despliegan al interior de la organización de los comicios, se estipuló que el ejercicio de ciertas atribuciones conferidas a los OPLE, como por ejemplo, lo concerniente a la impresión de documentos y producción de materiales electorales, implementación y operación del programa de resultados preliminares, realización de encuestas, sondeos de opinión y

cidió reasumir las funciones correspondientes a la capacitación electoral, así como la ubicación de las casillas y la designación de funcionarios de las mesas directivas en los procesos electorales locales, que constitucionalmente había delegado a los OPLE.

69 El Consejo General, mediante el Acuerdo INE/CG263/2014, del 19 de noviembre, expidió el actual Reglamento de Fiscalización, que abrogó el del 4 de julio de 2011. Con el Acuerdo INE/CG47/2015, del 28 de enero, el Consejo General instruyó a la Junta General Ejecutiva para desarrollar e implementar una aplicación informática que contribuya al cumplimiento de las obligaciones de los partidos políticos y candidatos, así como de las atribuciones que en materia de fiscalización tiene el INE.

70 Con el Acuerdo INE/CG341/2014, del 18 de diciembre, el Consejo General aprobó el presupuesto del INE para el ejercicio fiscal de 2015 y estableció las obligaciones y las medidas de racionalidad y disciplina presupuestaria; asimismo, mediante Acuerdo INE/ CG68/2015, del 25 de febrero, aprobó los Lineamientos de Incorporación de Servidores Públicos del INE y de los OPLE al Servicio Profesional Electoral Nacional.

${ }^{71}$ Por ejemplo, de conformidad con el artículo 41 constitucional, todo lo concerniente a derechos y acceso a prerrogativas de los partidos y los candidatos, preparación de la jornada electoral, materiales electorales, escrutinio y cómputo, declaración de validez y entrega de constancias de diputados y senadores, cómputo de la elección presidencial y demás atribuciones, son de ejercicio exclusivo del INE al interior de los comicios federales. En cambio, idénticas atribuciones, más lo concerniente a educación cívica, resultados preliminares, encuestas, sondeos, conteos rápidos, observación electoral, organización de los mecanismos de participación ciudadana y las demás que estipulen las leyes de las entidades federativas con motivo de los comicios estatales y que no estén expresamente reservadas al INE son de ejercicio exclusivo de los institutos electorales de los estados (apartado C del artículo 41). En ejercicio de sus atribuciones, el Consejo General del INE, mediante Acuerdo INE/CG101/2014, del 14 de julio, aprobó la Estrategia de capacitación y asistencia electoral para el proceso electoral 2014-2015. 
conteos rápidos, o la articulación de las actividades de observación electoral estarían sometidas a las reglas, lineamientos, criterios y formatos expedidos por el INE. ${ }^{72}$

El modelo de organización electoral se complementa con un par de competencias adicionales del INE al interior de las elecciones estatales. Por un lado, se encuentran aquellas competencias potestativas o condicionadas que presuponen el cumplimiento de los supuestos previstos en la ley y el acuerdo de ocho de los once consejeros electorales. Son competencias que permiten al INE asumir la completa función electoral de los estados o algunos de sus tramos (asunción total o parcial de competencias) ${ }^{73}$ o, en sentido contrario, delegar excepcionalmente el ejercicio de sus competencias originarias en los OPLE (delegación de competencias) $;^{74}$ reasumir el ejercicio de las mismas al terminar el proceso electoral o en cualquier momento de su desarrollo (reasunción de competencias) ${ }^{75}$ o ejercer la facultad de atracción sobre cualquier asunto de competencia estatal, siempre que sea "trascendente" o se requiera para sentar un "criterio de interpretación" relevante. ${ }^{76}$

En el extremo contrario se ubican las competencias obligatorias e incondicionadas, que imponen un mandato directo para que el INE las asuma, sin excepción alguna, destacando entre ellas la facultad para que desde el Consejo General se designen o remuevan al conjunto de consejeros electorales de los OPLE (artículo 32.2, inciso $b$, de la LGIPE). ${ }^{77}$

72 Estas competencias se encuentran estipuladas en el artículo 104 de la LGIPE. Derivado del Acuerdo INE/CG218/2014, del 22 de octubre, el Consejo General aprobó los Lineamientos para la impresión de documentos y producción de materiales electorales para las elecciones federales y locales, y con el Acuerdo INE/CG220/2014 de la misma fecha, el Consejo General estableció los Lineamientos y criterios generales para publicar encuestas por muestreo, encuestas de salida y/o conteos rápidos que se refieran a las preferencias electorales o consultas populares, durante los procesos electorales federales y locales. El Consejo General, con el Acuerdo INE/CG164/2014, del 30 de septiembre, estableció los Lineamientos para la acreditación y desarrollo de las actividades de los ciudadanos mexicanos que actuarán como observadores electorales en los procesos federal, locales, consultas populares y demás formas de participación ciudadana.

73 Los supuestos de la asunción total se encuentran en el artículo 121, mientras que los relativos a la asunción parcial en el 123, ambos de la LGIPE.

${ }^{74}$ Previo análisis y evaluación positiva por parte del INE de las capacidades profesionales, técnicas, humanas y materiales del OPLE, para asegurar el cumplimiento de la función de manera eficiente. Cfr. artículo 125.2 de la LGIPE.

75 Artículo 125.3 de la LGIPE.

76 Artículo 124, fracciones 3 y 4, de la LGIPE.

77 Durante 2014 el INE procedió a la designación de 133 consejeros electorales inte- 
Con base en los ajustes sintéticamente esbozados, el nuevo arreglo institucional vino a adquirir su configuración definitiva a través de progresivas decisiones del Consejo General del INE en las cuales reafirmó su vocación de autoridad electoral auténticamente nacional al reivindicar para sí - apenas unos meses después de la entrada en vigor de las leyes generales de la materia-, competencias en materia de organización, capacitación electoral y fiscalización que constitucionalmente se habían delegado al ámbito de los estados, o que potencialmente se encontraban en aptitud de ser delegadas, redefiniendo su espacio de actuación constitucional y su relación institucional con los OPLE. ${ }^{78}$

\section{Reflexión final}

Derivado de lo que se ha sostenido en este trabajo, es evidente que el tránsito de una autoridad electoral federal a una instancia de auténtica dimensión nacional — del IFE al INE - representó un punto de inflexión para el modelo de organización electoral en México. No obstante, esa transformación no produjo un viraje de ciento ochenta grados en las premisas sobre las que se asentaba el IFE en 1990 sino que las mismas, pro-

grantes de 19 OPLE. Derivado del Acuerdo INE/CG44/2014, del 6 de junio, el Consejo General aprobó los Lineamientos para la designación de consejeros presidentes y electorales de los OPLE, y con el Acuerdo INE/CG165/2014, del 30 de septiembre, aprobó la designación de dichos consejeros electorales; posteriormente, el Consejo General acató mediante Acuerdo INE/CG238/2014, del 29 de octubre, las sentencias de la Sala Superior del TEPJF en relación con la designación de los consejeros de los OPLE de los estados de Jalisco, Oaxaca, Sonora, Chiapas, Distrito Federal, Campeche.

78 Con el objeto de que las elecciones federales concurrentes con las locales pudieran llevarse a cabo a través de la instalación de una "casilla única", tal y como lo establece la LGIPE en su artículo 253.1, el Acuerdo INE/CG100/201, del 14 de julio, dispuso que el Instituto reasumiera las funciones correspondientes a la capacitación electoral, así como la ubicación de las casillas y la designación de funcionarios de la mesa directiva, bajo la justificación de "garantizar el cumplimiento de los principios rectores de la materia electoral, en particular el correspondiente a la certeza”. Mediante el Acuerdo INE/ CG114/2014, del 13 de agosto, se aprobó el Modelo de Casilla Única para las elecciones concurrentes que se celebrarán en junio de 2015. Algo similar sucedió en materia de fiscalización, en donde por Acuerdo INE/CG93/2014, del 9 de julio, se establecieron reglas transitorias de fiscalización que dejaron en manos de los institutos estatales electorales esta función, hasta la entrada en vigor del Reglamento de Fiscalización, por Acuerdo INE/CG263/2014, del 19 de noviembre, que dejó en claro el nuevo alcance nacional de las funciones de fiscalización. 
ducto de reformas electorales posteriores, o de decisiones impulsadas por las propias autoridades electorales, incluyendo las directrices jurisprudenciales del TEPJF, fueron modificando paulatinamente dichos elementos definidores para presentar, más de 23 años después, a una autoridad electoral sensiblemente distinta a aquella que se concibió en la década de los noventa.

En ese sentido, no hay duda que el ahora INE lejos está de representar una reedificación institucional desde la nada. Más bien es producto de una continuidad histórica que forma parte de un patrimonio que se ha forjado con la evolución de nuestra transición democrática, y que por virtud de la última reforma ha recogido lo más representativo del bagaje institucional afianzado por el IFE (por ejemplo, la fortaleza del personal de carrera de su Servicio Profesional Electoral), pero también, y hay que enfatizarlo, ha mantenido lo más característico de aquellas prácticas, dinámicas, inercias y diseños desafortunados que aunado al flagelo de la desconfianza, dejan entrever que el ciclo de vida de la nueva institución electoral parece perfilar nuevamente a una autoridad caracterizada por la sobrerregulación de su espacio de actuación institucional, por la sobreexposición de su arbitraje frente a los intereses de los actores políticos y demás sujetos regulados, y por la sobrevaloración de su capacidad transformadora de nuestra todavía incipiente realidad democrática.

En este sentido, es necesario preguntarse si el ámbito temporal de existencia de la nueva autoridad electoral debe caracterizarse por la presencia de una institución volcada permanentemente a sancionar a los sujetos directos e indirectos del proceso democrático, con un protagonismo político incesante, una capacidad de arbitraje sobre mayores y más complejas competencias, por el que discurran inexorablemente las soluciones a los problemas formales y sustanciales de nuestra democracia y con una capacidad para concentrar progresivamente la gestión de las elecciones a lo largo y ancho del país. No cabe duda que advertir con puntualidad la metamorfosis de este primer gran ciclo de institucionalidad electoral en México debería alertarnos de no cometer los mismos errores a la hora de orientar la ruta de actuación del naciente INE. 